\title{
Optimization of hydrocyclon for phosphatic rock separation using CFD
}

\section{Otimização de hidrociclones para separação de rocha fosfática via CFD}

Article Info:

Article history: Received 2021-05-04 / Accepted 2021-08-13 / Available online 2021-08-13

doi: $10.18540 /$ jcecvl7iss3pp12779-01-11e

\section{Resumo}

Felipe Orlando da Costa

ORCID: https://orcid.org/0000-0002-1973-8350

Federal University of Lavras, Brazil

E-mail: felipeorlandodacosta@gmail.com

Felipe Leonardo Barcelos Mateus

ORCID: https://orcid.org/0000-0002-6015-4795

Federal University of Lavras, Brazil

E-mail: felipe.1b.mateus@gmail.com

Irineu Petri Júnior

ORCID: https://orcid.org/0000-0001-5638-0370

Federal University of Lavras, Brazil

E-mail: irineupetri@gmail.com

Hidrociclones são equipamentos utilizados para a separação de sólido-líquido e líquido-líquido, através do fluxo centrífugo. A rocha fosfática é uma matéria-prima essencial para as indústrias de fertilizantes fosfatados, sendo que uma das etapas do beneficiamento desse minério é a concentração desse material utilizando os hidrociclones, devido a sua robustez e baixo custo de operação. Este trabalho utilizou da fluidodinâmica computacional para estudar modelos multifásicos para representar o escoamento multifásico do hidrociclone e possíveis modificações na geometria deste equipamento para otimizá-lo. Três modelos multifásicos foram estudados: Euleriano-Lagrangiano, Euleriano-Euleriano, e Modelo Mixture. Para otimizar o processo de separação e reduzir custos operacionais, foram propostas 11 modificações na geometria do $\mathrm{HC} 11$, denominadas B1, B2, B3, $\mathrm{C} 1, \mathrm{C} 2, \mathrm{C} 3, \mathrm{D} 1, \mathrm{D} 2, \mathrm{E} 1, \mathrm{E} 2$ e E3, sendo as 8 primeiras mudanças no vortex finder e as 3 últimas a adição de uma parede na região de formação do air core. A geometria e a malha foram geradas no software GAMBIT ${ }^{\circledR}$ e a simulação foi realizado no software FLUENT ${ }^{\circledR}$ 19.2. Para comparar a eficiência dos modelos multifásicos foram utilizadas as eficiências individuais e globais de coleta e valores experimentais da literatura. O modelo Mixture apresentou o menor erro relativo, e foi utilizado nas simulações seguintes. Os parâmetros avaliados para medir a otimização do HC11 foram a queda de pressão $(\Delta \mathrm{P})$, a razão de líquido $\left(\mathrm{R}_{\mathrm{L}}\right)$ e a eficiência global $(\eta)$. Os resultados foram comparados com o valor encontrado nas simulações do HC11 para avaliar a otimização. Verificouse que as modificações B2. B3 e D1 melhoraram todos os parâmetros avaliados, otimizando o processo de separação e reduzindo os custos de energéticos envolvidos na operação.

Palavras-chave: vortex finder, air core, eficiência global

\section{Abstract}

Hydrocyclones are equipment for the separation of solid-liquid and liquid-liquid mixtures through the centrifugal flow. The phosphate rock is an essential raw material to the industry of phosphate fertilizers. The mineral needs to be concentrated in its processing, and this can be done through hydrocyclones, considering its robustness and low operation costs. This work aimed to use the computational fluid dynamics to study different multiphase models to represent the hydrocyclones, as well as modifications to its geometry to increase its efficiency. Three multiphase models were studied in order to analyze their efficiency in simulating the separation through hydrocyclones: Eulerian-Lagrangian, Eulerian-Eulerian, and Mixture Model. In order to optimize the separation 
process and reduce operating costs, 11 modifications were proposed in the geometry of $\mathrm{HC} 11$, called B1, B2, B3, C1, C2, C3, D1, D2, E1, E2 and E3. The first 8 proposals involved changes in the vortex finder and the last 3 proposals added a wall in the air core formation region. Geometry and mesh were generated in the GAMBIT ${ }^{\circledR}$ software and the simulation was made in the FLUENT $^{\circledR} 19.2$ software. In order to compare the multiphase models, the individual and overall efficiency were used along with the experimental results. The Mixture model had the smallest relative error and was used for the subsequent simulations. The parameters evaluated to measure the optimization of HC11 were the pressure drop $(\Delta \mathrm{P})$, the liquid ratio $\left(\mathrm{R}_{\mathrm{L}}\right)$ and the overall efficiency $(\eta)$. The results obtained for each of the proposals were compared with the value found in the HC11 simulations to evaluate the possible optimization. With that, it was possible to verify that modifications B2, B3, and D1 improved all the parameters evaluated, optimizing the separation process and reducing energy costs involved in the operation.

Keywords: vortex finder, air core, overall efficiency

\section{Nomenclature}

$$
\begin{aligned}
& \mathrm{R}_{\mathrm{L}}-\text { Liquid Ratio } \\
& \Delta \mathrm{P}-\text { Pressure drop } \\
& \eta-\text { Overall efficiency }
\end{aligned}
$$

\section{Introduction}

Hydrocyclones belong to an important group of equipment intended for the separation of solid-liquid and liquid-liquid mixtures through a centrifugal field. They were invented to solve the problems that involve the separation of solid and/or immiscible fluids with different compositions and densities (Chiné and Concha, 2000).

The phosphate rock is an essential raw material to the industry of phosphatic fertilizers. The main composition of this mineral is the phosphorous pentoxide $\left(\mathrm{P}_{2} \mathrm{O}_{5}\right)$. The phosphate rock is rich in apatite minerals, and, after its beneficiation, the material is denominated as phosphate concentrate. In the ore beneficiation process, hydrocyclones are used to concentrate this material, due to its robustness and low operating cost (Silva, 2014; Vieira, 2006).

The CFD (Computational Fluid Dynamics) can be succinctly described as a methodology which uses numerical methods to solve conservation equations to represent a real system. The application of a numerical method can also be divided into three main steps: pre-processing, processing, and post-processing. In the pre-processing stage, the geometric domain is defined and then divided, thus forming the mesh. In this step, the physical properties of the fluid and other parameters necessary to solve the problem can be defined. In the processing phase, a solver based on the numerical model is applied to obtain the quantities of interest. In the post-processing stage, the results are analyzed to verify the validity of the numerical model by comparisons with the experimental results (Lima, 2005).

For the use of CFD in the simulation of hydrocyclones there are two main numeric models: Eulerian-Lagrangian and Eulerian-Eulerian. Inside the latter, there is the Mixture model. For Eulerian-Lagrangian approach, the incompressible flow of the continuous phase is obtained through the Navier-Stokes equations with a temporal average (Reynolds Averaged Navier-Stokes - RANS) and the movement of the disperse phase (particles, bubbles, droplets) is obtained by integrating the force balances for each particle in the simulation (Yadigaroglu and Hewitt, 2018).

The Eulerian-Eulerian multiphase model allows for the modelling of multiple phases that interact with each other. These phases can be solids, liquids and gases in practically any combination. The Mixture model is a simplified model with the Eulerian-Eulerian approach. Its main advantage is its capability in modelling both fluid and particulate phases simultaneously, solving the momentum, continuity, and energy equations for the mixture. The Mixture model is a good substitute for the standard Eulerian-Eulerian model when the interface laws are unknown or not clearly defined. The typical application for this model includes sedimentation, cyclonic 
separators, fluxes with particulates of low load and bubbling flows in which the volumetric fraction of gases are low (Ansys, 2018).

Vieira et al. (2008) studied through CFD and experimental analysis the optimizations to the geometry of hydrocyclones proposed by Vieira (2006), in which the optimizations of the geometric relations allowed for a simultaneous lowering of the Euler number and cut size diameter. The work of Silva (2012) also addressed alterations to the geometry of hydrocyclones aiming for the optimization of the separation process. It also proposed alterations to the vortex finder thickness and shape, the use of a feeding ramp and the use of rotational feeding. These alterations resulted in performance gains compared to standard hydrocyclones. Furthermore, with the use of a response surface technique combined with a differential evolution algorithm, three new geometries for the hydrocyclone were found.

This work aims to study, through CFD, the efficiency of each multiphase model (EulerianLagrangian, Mixture model, Eulerian-Eulerian) in simulating an HC11 hydrocyclone operating with phosphate rock and air. It also aims to analyze the optimization of the separation process and to reduce the pressure loss through changes made in the HC11 hydrocyclones. 11 modifications were proposed in the geometry of $\mathrm{HC} 11,8$ proposals involving changes in the vortex finder and the last 3 proposals adding a wall in the region where the air core is formed. $R_{L}$ and $\eta$ are used to evaluate the optimization of the separation process and the pressure drop is used to evaluate the reduction in energy costs.

\section{Material and Methods}

\subsection{Multiphase Models}

The simulations were based on the experimental data from Vieira (2006) by comparing the numeric results with the experimental results. The geometry and mesh construction were made in the GAMBIT ${ }^{\circledR}$ 2.3.16 software, and the simulation was carried out in FLUENT ${ }^{\circledR}$ 19.2. For the proper use of the mesh, the meshes and turbulence models were tested for all multiphase models, and the optimized mesh and turbulence models were used.

The 3D computational meshes are presented in Figure 1.a and Figure 1.b, and the dimensions of the hydrocyclone are described in Figure 1.c and Figure 1.d. The boundary and initial conditions used are presented in Table 1.
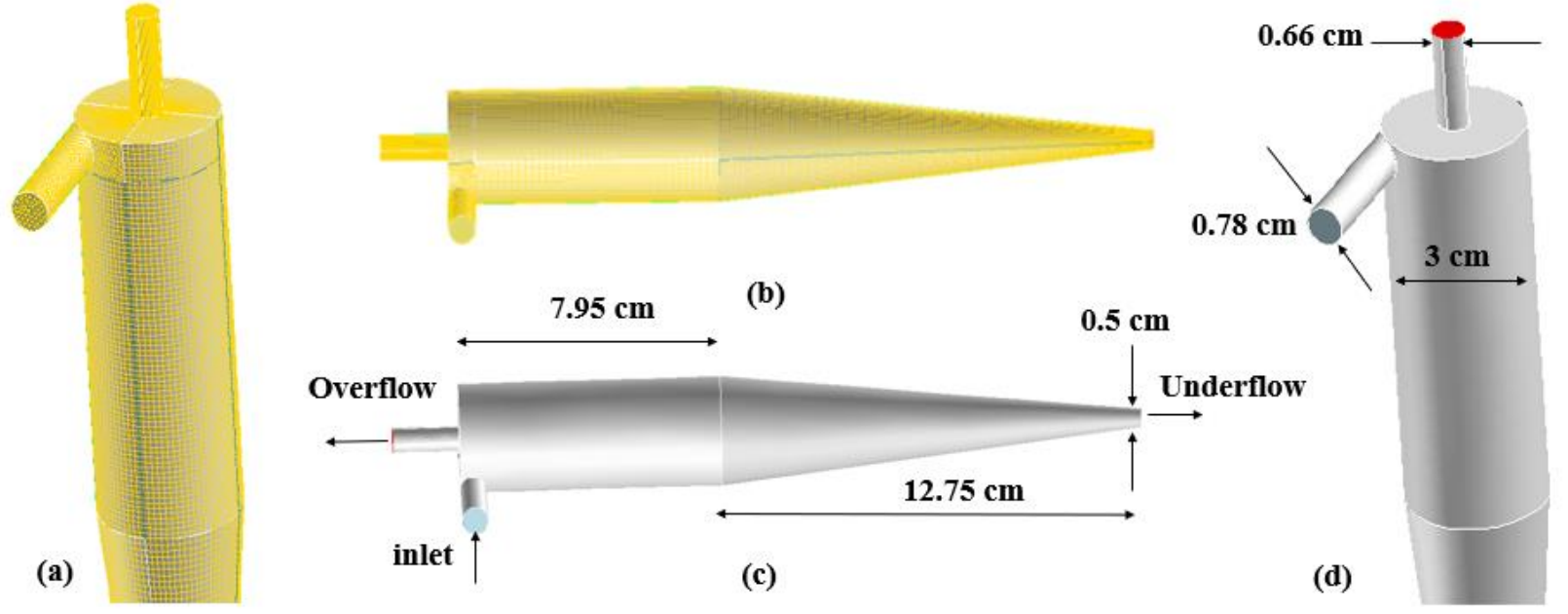

Figure 1 - (a) isometric view and (b) right side view of the computational mesh, (c) isometric view of the geometry and radial dimensions, and (d) right side view of the geometry and axial dimensions. 
Table 1 - Boundary and initial conditions used in FLUENT ${ }^{\circledR} 19.2$

- Transient 3D simulation - Atmospheric pressure in Uberlândia/MG (92800 Pa)

- Feed flow (Water): $0.3124 \mathrm{~kg} / \mathrm{s}$

- Feed flow (Phosphate rock): $0.0093 \mathrm{~kg} / \mathrm{s}$

- Discretization method for the momentum: First Order Upwind

- Discretization method for the pressure: PRESTO!

\begin{tabular}{l|l}
\hline - Relaxation factors (Petri et al, 2009) & $\begin{array}{l}\text { Pressure }=0.3 \\
\text { Density }=1 \\
\text { Momentum }=0.1\end{array}$ \\
\hline - Convergence criterion $=10^{-4}$ & \\
\hline - Time Step Size $(\mathrm{s})=10^{-6}$ a $10^{-5}$ & \\
\hline
\end{tabular}

The injected particles in the hydrocyclone were defined as phosphate rock, with a particle size distribution modelled by the Rosin-Rammler-Bennet (RRB) model, with $\mathrm{D}^{\prime}=12,88 \mu \mathrm{m}$ and $\mathrm{n}=$ 0,81 as defined by Vieira (2006). The particle injections are part only of the Eulerian-Lagrangian model, and its use is only possible because of the low volumetric concentration of phosphate rock in the flow, as shown in Table 1.

For a better comparison of the results obtained for the Lagrangian approach, for all three models, five different diameters equally spaced in the range of 0.3 to $50 \mu \mathrm{m}$ were simulated. These values are referring to the minimum and maximum diameter values for the phosphate rock. Therefore, the simulated diameters were: $0.3,12.7,25.2,37.6$ and $50.0 \mu \mathrm{m}$. For each diameter the individual efficiency $(\bar{\eta})$ and overall efficiency $(\eta)$ were calculated.

For the use of the Eulerian-Eulerian and Mixture models the system is three-phased, composed by water, air, and phosphate rock. For a proper representation of the system, it is necessary to describe the behavior of the granular phase, and to model the interactions between the phases. Thus, the proper models are selected to predict the behavior of the granular phase, which is described through the granular viscosity, bulk granular viscosity, frictional viscosity, frictional pressure, solid pressure and radial distribution. The modelling of the phase interactions, on the other hand, is described through the drag, turbulent dispersion, turbulent interaction, superficial tension and interfacial area. Tables 2 and 3 contain the utilized models to describe the granular phase and the phase interaction, respectively.

Table 2 - Parameters and models used in the Eulerian-Eulerian and Mixture models for Phosphate rock

\begin{tabular}{ccccc}
\hline & \multicolumn{2}{c}{ Eulerian Model } & \multicolumn{2}{c}{ Mixture Model } \\
\hline & Model & Reference & Model & Reference \\
\hline Granular Viscosity $(\mathrm{kg} / \mathrm{m} . \mathrm{s})$ & Syamlal-obrien & O'Brien and Syamlal & Syamlal-obrien & O'Brien and Syamlal \\
Granular Bulk Viscosity (kg/m.s) & Lun-et-al & Lun et al., (1984) & N/A & N/A \\
Frictional Viscosity (kg/m.s) & Schaeffer & Schaeffer (1987) & N/A & N/A \\
Frictional Pressure (Pa) & Syamlal-et-al & Syamlal et al., (1993) & N/A & N/A \\
Solids Pressure (Pa) & Lun-et-al & Lun et al., (1984) & Lun-et-al & Lun et al., (1984) \\
Radial Distribution & Lun-et-al & Lun et al., (1984) & Lun-et-al & Lun et al., (1984) \\
\hline
\end{tabular}


Table 3 - Models for the phase interaction for Eulerian-Eulerian and Mixture models.

\begin{tabular}{|c|c|c|c|c|c|c|}
\hline \multicolumn{7}{|c|}{ Eulerian Model } \\
\hline & \multicolumn{2}{|c|}{ Air-water } & \multicolumn{2}{|c|}{ Particle-water } & \multicolumn{2}{|c|}{ Particle-air } \\
\hline & Model & Reference & Model & Reference & Model & Reference \\
\hline Drag & S.-naumann & $\begin{array}{c}\text { Schiller and Naumann } \\
\text { (1935) }\end{array}$ & Wen-yu & $\begin{array}{l}\text { Wen and Yu } \\
\text { (1966) }\end{array}$ & Wen-yu & $\begin{array}{l}\text { Wen and } \mathrm{Yu} \\
\text { (1966) }\end{array}$ \\
\hline T. Dispersion & $\begin{array}{l}\text { Diffusion-in- } \\
\text { vof }\end{array}$ & $\begin{array}{c}\text { Sokolichen et al., } \\
\text { (2004) }\end{array}$ & $\begin{array}{l}\text { Diffusion-in- } \\
\text { vof }\end{array}$ & $\begin{array}{l}\text { Sokolichen } \\
\text { et al., (2004) }\end{array}$ & N/A & N/A \\
\hline T. Interaction & Simonin-et-al & $\begin{array}{l}\text { Simonin and Viollet } \\
\text { (1990) }\end{array}$ & none & N/A & N/A & N/A \\
\hline Surface Tension & $0.073 \mathrm{~N} / \mathrm{m}$ & Aragão et al., (2020) & none & N/A & none & N/A \\
\hline Interfacial Area & ia-gradient & N/A & ia-gradient & N/A & ia-gradient & N/A \\
\hline \multicolumn{7}{|c|}{ Mixture Model } \\
\hline & \multicolumn{2}{|c|}{ Air-water } & \multicolumn{2}{|c|}{ Particle-water } & \multicolumn{2}{|c|}{ Particle-air } \\
\hline & Model & Reference & Model & Reference & Model & Reference \\
\hline Drag & S.-naumann & $\begin{array}{l}\text { Schiller and Naumann } \\
\text { (1935) }\end{array}$ & Wen-yu & $\begin{array}{l}\text { Wen and } \mathrm{Yu} \\
\text { (1966) }\end{array}$ & N/A & N/A \\
\hline Slip & Manninen-et-al & Carvalho et al., (1991) & Manninen-et-al & N/A & N/A & N/A \\
\hline Surface Tension & $0.073 \mathrm{~N} / \mathrm{m}$ & Aragão et al., (2020) & none & N/A & none & N/A \\
\hline Interfacial Area & ia-gradient & N/A & ia-gradient & N/A & ia-gradient & N/A \\
\hline
\end{tabular}

\subsection{Geometry Modifications}

The influence of the geometry changes in the pressure drop $(\Delta \mathrm{P})$ and in the liquid ratio $\left(\mathrm{R}_{\mathrm{L}}\right)$ was evaluated using the LES turbulence model and the VOF multiphase model. The multiphase model was used to predict the formation of air cores. To determine the overall efficiency $(\eta)$ the LES turbulence model and the Mixture multiphase model were used, while the multiphase model was used to predict the flow of phosphatic rock, which is a particulate material according to Costa and Petri Junior (2019).

The geometry and computational meshes were also generated using the commercial software GAMBIT $^{\circledR}$ version 2.3.16, and the simulations were carried out in the FLUENT $^{\circledR} 19.2$ software. Its conditions were the same used for the multiphase models tests as shown in Table 1.

The phosphate rock particles injected into the hydrocyclone for the geometry modifications tests had the same particle size distribution used for the modelling tests given by the RRB model, with parameters $\mathrm{D}^{\prime}=12.88 \mu \mathrm{m}$ and $\mathrm{n}=0.81$ according to Vieira (2006).

Eleven modifications were proposed in the hydrocyclone geometry, each called B1, B2, B3, $\mathrm{C} 1, \mathrm{C} 2, \mathrm{C} 3, \mathrm{D} 1, \mathrm{D} 2, \mathrm{E} 1, \mathrm{E} 2$ and E3. Eight of them involved changes to the vortex finder and 3 of them added a wall in the air core formation region. The representation of all the proposals are contained in Figure 2. The dimensions were based on the work of Hwang and Chou (2017).

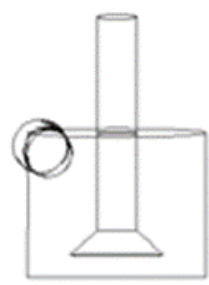

B1

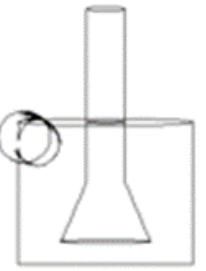

B2

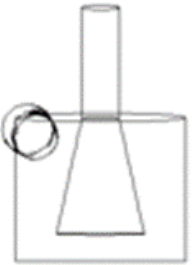

B3 (a)

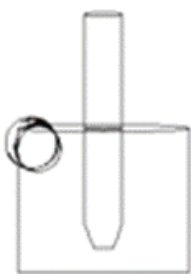

C1

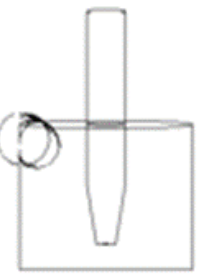

C2

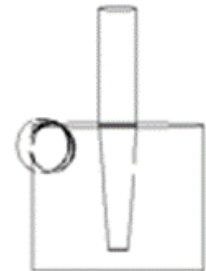

C3 


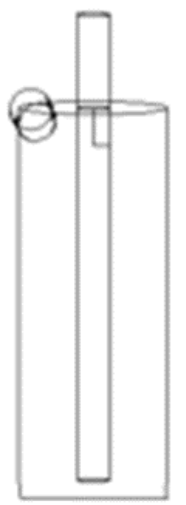

D1

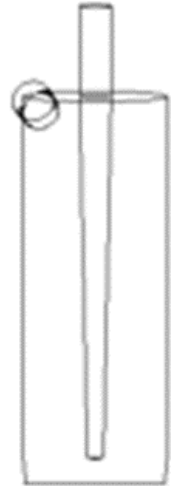

D2

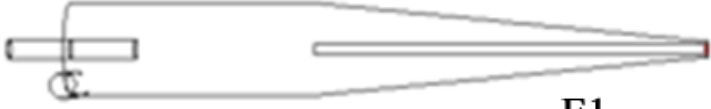

E1

(c)

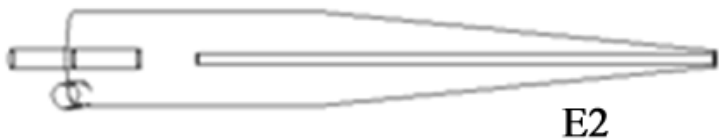

(d)

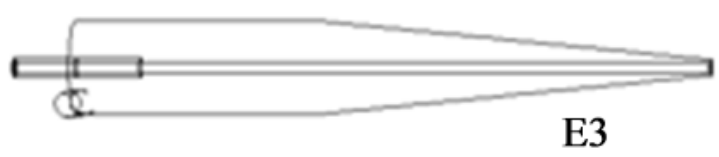

Figure 2 - Geometry of the modifications made to (a) package $B$, (b) package $C$, (c) package $D$ and (d) package $E$.

\section{Results and Discussion}

\subsection{Multiphase Models}

Table 4 presents the values of individual efficiency for all three models in 5 different diameters. It was also possible to calculate the relative error for the models by comparing the efficiencies with the overall efficiency of $70 \%$ obtained by Vieira (2006). Table 4 contains the mass fractions and overall efficiency for the models.

As shown in Table 4, the collected mass fractions are bigger in intermediate values of the diameter. For the Lagrangian model, with higher diameter values, the values of $\bar{\eta}$ decreased, which is not an appropriate behavior for a hydrocyclone, as with bigger diameters, the terminal velocity of the particle is also increased, implying the increase of the individual efficiency. This can be affirmed only since the density for all diameters are the same.

For the Eulerian-Eulerian and Mixture models, the increase of the diameter resulted in an increase of the $\bar{\eta}$ values as expected for the operation. Table 5 contains the values of $\eta$ for each model and its respective relative errors.

Through Table 5 it is possible to conclude that the Lagrangian approach is not enough to adequately simulate the particulate collection in the hydrocyclone considering the relative error values. This was expected due to the inconsistencies previously observed in the values of $\bar{\eta}$.

Table 4 - Mass fractions and individual efficiencies for the utilized models.

\begin{tabular}{ccccc}
\hline & & $\begin{array}{c}\text { Lagrangian } \\
\text { Model }\end{array}$ & $\begin{array}{c}\text { Eulerian } \\
\text { Model }\end{array}$ & $\begin{array}{c}\text { Mixture } \\
\text { Model }\end{array}$ \\
\hline Diameter $(\boldsymbol{\mu m})$ & Fraction & $\overline{\boldsymbol{\eta}}(\boldsymbol{\%})$ & $\overline{\boldsymbol{\eta}}(\boldsymbol{\%})$ & $\overline{\boldsymbol{\eta}}(\boldsymbol{\%})$ \\
\hline 0.3 & 0.049 & 95.18 & 44.46 & 44.68 \\
12.7 & 0.613 & 100.00 & 51.65 & 54.64 \\
25.2 & 0.202 & 98.19 & 69.11 & 77.35 \\
37.6 & 0.091 & 82.53 & 86.30 & 94.58 \\
50.0 & 0.045 & 80.10 & 95.52 & 99.63 \\
\hline
\end{tabular}

Table 5 - Overall efficiency and its respective relative error for the utilized models.

\begin{tabular}{ccc}
\hline Model & $\boldsymbol{\eta}(\boldsymbol{\%})$ & Relative Error $(\boldsymbol{\%})$ \\
\hline Lagrangian & 96.91 & 38.44 \\
Eulerian & 59.96 & 14.34 \\
Mixture & 64.41 & 7.98 \\
\hline
\end{tabular}


For the Eulerian-Eulerian model the results were coherent with an $\eta$ relatively close to the experimental value of $70 \%$ as an intermediate relative error. The lack of performance for this model in comparison to the Mixture model is due to the lack of explicit information for the interface laws involving the drag and superficial tension between the phases. Additionally, some of the utilized sub-models for phase interactions are ones that were not fully explored in the literature.

The Mixture model had the best results with the lowest relative error, with reasonably good convergence of the simulated and experimental value. As a comparison, the error between numeric and experimental results for the work of Silva (2012) simulating a solid-liquid separation with hydrocyclones were approximately 10\%. Thus, the error obtained for the Mixture Model in this work can be considered to be relatively low. However, for both Mixture and Eulerian-Eulerian modelling, the relative error could still be minimized by simulating more diameter values between the minimum and maximum range, since it would better represent the real system. Another possibility for reducing the relative error is the attainment of certain parameters that are still not found in the literature, such as the superficial tension between the air and the phosphatic rock and between the water and the phosphatic rock.

\subsection{Geometry Modifications}

The values obtained in the HC11 simulation are used as reference. The mesh partition method used was Spherical Axes, since it minimizes the simulation time according to Costa et al. (2020).

The mesh independence test for the hydrocyclone was carried out, and a value of approximately 222000 elements was obtained. The analysis of the turbulence models was carried out as well, and with it, it was observed that the LES model is the one that best models the turbulence in the interior of the equipment. As stated previously, the Mixture model is the best for the multiphase modelling of the hydrocyclone. Consequently, the LES and Mixture models were used to obtain $\Delta \mathrm{P}, \mathrm{R}_{\mathrm{L}}$, and $\eta$ for the modifications in the geometry. Table 6 contains the average values of $\Delta \mathrm{P}, \mathrm{R}_{\mathrm{L}}$ and $\eta$ for all different geometries, and the experimental and simulated results for the $\mathrm{HC} 11$ in order to evaluate the optimization of the parameters.

Table 6 - Average values of $\Delta P, R_{L}$, and $\eta$ for all modifications in the geometry.

\begin{tabular}{cccc}
\hline Simulations & $\boldsymbol{\Delta \mathbf { P } ( \mathbf { k g f } / \mathbf { c m } ^ { 2 } )}$ & $\mathbf{R}_{\mathbf{L}}(\boldsymbol{\%})$ & $\boldsymbol{\eta} \mathbf{( \% )}$ \\
\hline Experimental & 1.50 & 32.07 & 70.00 \\
HC11 & 1.53 & 36.90 & 64.41 \\
B1 & 2.31 & 40.60 & 72.22 \\
B2 & 1.47 & 35.10 & 70.53 \\
B3 & 1.30 & 34.20 & 68.54 \\
C1 & 2.68 & 84.70 & 87.35 \\
C2 & 2.42 & 82.60 & 87.6 \\
C3 & 2.84 & 83.80 & 86.06 \\
D1 & 1.23 & 33.80 & 69.57 \\
D2 & 2.17 & 85.10 & 86.33 \\
E1 & 1.48 & 38.20 & 59.08 \\
E2 & 1.31 & 36.80 & 62.36 \\
E3 & 1.08 & 34.80 & 61.26 \\
\hline
\end{tabular}

In order to validate the models used to predict the hydrocyclone parameters it is necessary to compare the $\Delta \mathrm{P}, \mathrm{R}_{\mathrm{L}}$, and $\eta$ for the experimental HC11 [values obtained in Vieira, (2006)] and the simulated $\mathrm{HC} 11$. With that, it was obtained a relative error of $2.01 \%$ for the $\Delta \mathrm{P}, 15.10 \%$ for the $\mathrm{R}_{\mathrm{L}}$ 
and $7.98 \%$ for the $\eta$. These results are not yet optimal according to previous results in the literature, but still represent relatively low errors for numeric simulations. With this statement, the HC11 hydrocyclone model can be used to analyze the modifications in the geometry using only CFD.The optimization of the HC11 separation process occurs when there is a reduction in the $\mathrm{R}_{\mathrm{L}}$ and an increase in the $\eta$. To minimize energy costs, it is necessary to have a reduction in the $\Delta P$. Thus, analyzing the results contained in Table 6 , it can be noted that the B2, B3 and D1 modifications improved all the parameters evaluated in the optimization. With that it is possible to conclude that changing the geometric shape of the vortex finder of a cylinder for one cone trunk with positive angulation or a cylinder coupled to a cone trunk with positive angulation benefits the HC11. However, the angulation must be smoother. This can be concluded by observing the results for the B1 modification, in which there is a vortex finder consisting of a cylinder coupled to a cone trunk with positive angulation, but that cone trunk has a high angle, and with that the $\mathrm{R}_{\mathrm{L}}$ was damaged.

For the modification package $\mathrm{C}$, where the vortex finder is constituted of a cone trunk with negative angulation or a cylinder coupled to a cone trunk with negative angulation, the separation process and the operation cost of the equipment were impaired. Thereby it is possible to conclude that a cone trunk with negative angulation results in lower efficiency in the equipment from the energy and separation point of view. That happens because the lower diameter of the vortex finder is very low, and with that, the flow in the overflow decreases. Thus, there is a reduction in speed, so by Bernoulli's principle there is an increase in pressure, increasing energy costs. Also, due to the low lower diameter of the vortex finder, it becomes more difficult for fluid and particles to flow through the overflow, so there is an increase in $\eta$ simultaneous to an increase in $R_{L}$ which impairs the separation process.

For package $\mathrm{D}$, the length of the vortex finder is equal to the length of the cylindrical region of the HC11. In that package it is seen that when the same geometric shape is maintained there is an optimization for the equipment, but changing the shape for a trunk of cone with negative angulation damages the efficiency of the equipment due to the same reasons specified for the $C$ package.

For the modification package $\mathrm{E}$ a wall was inserted in the air core formation region with the aim of avoiding the mixing of particles that are in the air stream, leaving the overflow with the water inside the hydrocyclone. Analyzing the $\Delta \mathrm{P}$, the energy costs were minimized. However, it damaged the separation process. The main objective was the optimization of the separation, since, considering an industry, the energy consumption of a hydrocyclone is always lower than the total energy cost of the industry. However, it is worth noting that for the E1 and E2 modifications the pipe in the air core formation region has prevented the mixing of air with water, but that did not optimize the separation process. Figure 3 contains the volume fraction of air to show that the mixture between air and water was prevented. In modification E3 that did not occur due to a decrease in the $\mathrm{R}_{\mathrm{L}}$ when compared to others in that package, therefore, there is an increase in the volumetric flow in the overflow, preventing the passage of air in this region. 


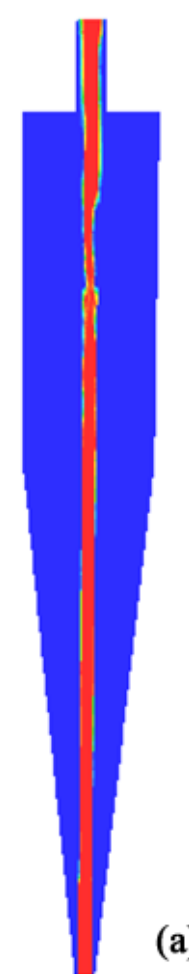

(a)

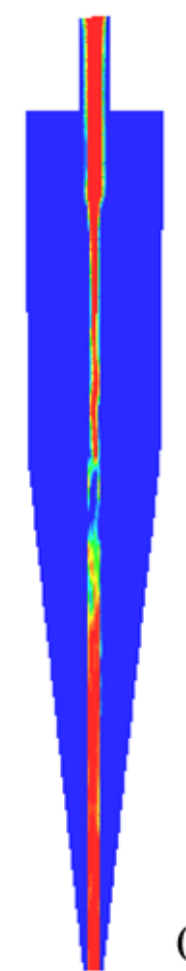

(b)
Volume fraction (air)

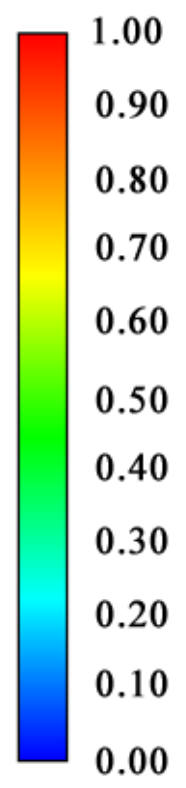

(c)

Figure 3 - Volume fraction for the air of modifications (a) E1, (b) E2 and (c) E3.

\section{Conclusions}

Thus, this work was able to determine that the Eulerian-Lagrangian model does not properly represent the flow in the HC11 hydrocyclone. The Mixture model was found to be the best model for the flow with the lowest relative error of $7.98 \%$, since its simplifications overcome some problems related to the lack of information of interface laws, such as drag and superficial tensions between the phases.

Therefore, the model used for the hydrocyclone was first validated through comparison between experimental data of the $\mathrm{HC} 11$ and the simulation data, and small values of relative errors were obtained, thus validating the turbulence and multiphase models used for hydrocyclone as well. This way, it was possible to evaluate the modifications in the geometry of the HC11 using CFD.

For the modifications in the geometry, it can be concluded that the modifications B2, B3, and D1 optimized the separation process and minimized the energy cost involved in the process. Changing the geometric shape of the vortex finder for a cone trunk with positive angulation and increasing the length of the vortex finder benefited the HC11, but the insertion of a wall in the air core region and the change of geometric shape of the vortex finder into a cone trunk with negative angulation damaged the results for the HC11.

For the validation of these results, the ideal is the assembly of an experimental line, so that it can be proved that these new configurations of HC11 have improved their operation.

\section{Acknowledgements}

This work was supported by the, Foundation for Research Support of Minas Gerais (FAPEMIG) project number APQ-00022-18, National Council for Scientific and Technological Development (CNPq) project number 427962/2018-8 and Federal University of Lavras (UFLA) project numbers PIDEG357-2018 and PIDEG76-2018, the authors are grateful to the for their financial support. 


\section{References}

Ansys, Inc. Fluent User's Guide and Theory Guide. Canonsburg: [s.n.], 2018.

Aragão, M. M. C. A., Neto, S. R. F., Leite, B. E. (2020). Comportamento fluidodinâmico da interface água- ar: Modelagem e simulação. O Empoderamento Científico e seus Aspectos Inovadores, Editora Poisson

Carvalho, M. G., Farias, T., Fontes, P. (1991). Predicting Radiative Heat Transfer in Absorbing, Emitting, and Scattering Media Using the Discrete Transfer Method. Fundamentals of Radiation Heat Transfer. 160(1), 17-26. ISBN: 0791807304

Chiné, B.,Concha, F. (2000). Flow patterns in conical and cylindrical hydrocyclones. Chemical Engineering Journal, 80(1-3), 267-273. https://doi.org/10.1016/s1383-5866(00)00101-5

Costa, F. O., Barcelos Mateus, F. L., Petri Júnior, I. (2020). Influencia en el costo computacional de los métodos de fraccionamiento empleados en CFD para la simulación de hidrociclones. The Journal of Engineering and Exact Sciences, 6(4), 0528-0532. https://doi.org/10.18540/jcecvl6iss4pp0528-0532

Costa, F. O., Petri Júnior, I. (2019). Influência dos modelos multifásicos na eficiência total via CFD no escoamento de hidrociclone. Blucher Chemical Engineering Proceedings. XIII Congresso Brasileiro de Engenharia Química em Iniciação Científica. https://doi.org/10.5151/cobecic2019-socp7.

Hwang, K.-J., \& Chou, S.-P. (2017). Designing vortex finder structure for improving the particle separation efficiency of a hydrocyclone. Separation and Purification Technology, 172, 7684. https://doi.org/10.1016/j.seppur.2016.08.005

Lima, R. C. (2005). Simulação de Grandes Escalas de Escoamentos Incompressíveis com Transferência de Calor e Massa por um Método de Elementos Finitos e Subdomínios. Dissertação de Mestrado, Universidade Estadual Paulista, São Paulo, SP, Brasil.

Lun, C. K. K., Jeffrey, D. J., Chepurniy N. (1984). Kinetic Theories for Granular Flow: Inelastic Particles in Couette Flow and Slightly Inelastic Particles in a General Flow Field. J. Fluid Mech. 140(1), 223-256. doi:10.1017/S0022112084000586

O'Brien, T. J., Syamlal, M. (1993). Particle Cluster Effects in the Numerical Simulation of a Circulating Fluidized bed. $4^{\text {th }}$ International CFB Conference, Pennsylvania, USA.

Petri Júnior I., Duarte C. R., \& Vieira L.G. M. (2009). Aplicações das técnicas de CFD para predição da distribuição de vazões volumétricas em hidrociclones dispostos em distintas baterias. Congresso Brasileiro de Sistemas Particulados, Campinas, Brasil.

Raposo, G. M. (2008). Simulação Numérica do Escoamento em Hidrociclone Destinado a Aplicação de Alto Teor de Óleo. Dissertação de Mestrado, Pontifícia Universidade Católica do Rio de Janeiro, Rio de Janeiro, RJ, Brasil.

Schaeffer, D. G. (1987). Instability in the evolution equations describing incompressible granular flow. Journal of Differential Equations, 66(1), 19-50. https://doi.org/10.1016/00220396(87)90038-6

Schiller, L., Naumann, Z. (1935). A Drag Coefficient Correlation. VDI Zeitung, 77, 318-320.

Silva, D. O. (2012). Otimização da separação sólido-líquido em hidrociclones mediante modificações geométricas. Tese de Doutorado. Universidade Federal de Uberlândia, Uberlândia, MG, Brasil.

Silva, N. K. G. (2014). Estudo de otimização da configuração do hidrociclone filtrante. Dissertação de Mestrado. Universidade Federal de Uberlândia, Uberlândia, MG, Brasil.

Simonin, O., Viollet, P. L. (1990). Predictions of an Oxygen Droplet Pulverization in a Compressible Subsonic Coflowing Hydrogen Flow. Numerical Methods for Multiphase Flows. 91(1), 65-82.

Sokolichen A., Eigenberger, G., Lapin, A. (2005). Simulation of Buoyancy Driver Bubbly Flow: Established Simplifications and Open Questions. Journal Review, AIChE Journal. 50(1), 2445. https://doi.org/10.1002/aic.10003

Symlal, M., Rogers, W., O’Brien T. J. (1993). MFIX Documentation: Volume 1, Theory Guide. National Technical Information Service, Springfield, https://doi.org/10.2172/10145548 
Vieira, L. G. M., Damasceno, J. J. R., \& Barrozo, M. A. S. (2008). Filtration on Hydrocyclone of Optimized Geometric Relationships. Materials Science Forum, 591-593, 341-346. https://doi.org/10.4028/www.scientific.net/msf.591-593.341

Vieira, L. G. M. (2006) Otimização dos Processos de Separação em Hidrociclones Filtrantes. Tese de Doutorado. Universidade Federal de Uberlândia, Uberlândia, MG, Brasil.

Wen, C. Y., Yu, Y. H. Yu. (1966). Mechanics of Fluidization. Chem. Eng. Prog. Symp. Series. 62(1), 100-111.

Yadigaroglu, G., Hewitt G. F. (2018). Introduction to Multiphase Flow. Springer. 